\title{
FACTS FOR THE EU SECURITY CONCEPT
}

\author{
Dana PROCHÁZKOVÁ ${ }^{1}$
}

Review article

$\begin{array}{ll}\text { Abstract: } & \text { The paper deals with the EU security. On the basis of evaluation of data in detail studies } \\ \text { under the project FOCUS it gives the facts for the EU security concept. }\end{array}$

\section{Introduction}

Present goal of humans in the EU is to live at a safe space with development potential. Therefore, the basic function of the EU and its Member States is to provide the protection and development of the human society. The EU has been realizing so-called good governance. Within the $7^{\text {th }}$ framework, a lot of research projects have been solved. The projects are focused on security and sustainable development of the area of interest. One of the projects is the project FOCUS. In this project there are predicted possible disaster scenarios focused on identifying possible situations in the area and on providing a level of prevention, preparedness, response and recovery so that the system of applied actions and activities would not lead to the safety reduction and could be realized in terms of knowledge and in financial and technical terms.

After the experience with several crises of different types in recent years, it is clear that the EU security concept and internal framework must change. They must cover not only the internal market but also other domains supporting the real economy and also systemic support for the European population. One of such aims is to build a safe community with sufficient sustainability. The basic terms security and safety are defined by the following way: the security denotes the state of asset in which the harm origin probability is low; the safety denotes the set of anthropogenic measures and activities by which asset security is ensured (Nicholson et al., 2012, Procházková, 2008, Procházková, 2011a; Procházková, 2012; Rogers, 2011).

\section{Materials and methods}

Data on disasters, disaster management are given in quoted materials. The synthesis of results derived by comprehensive approach from 15 different investigations (Procházková, 2011a-g) is described in following paragraph.

\section{Groundwork}

Based on current knowledge of human life, it is not enough to meet physiological needs. H. Maslow (1954) showed that there are further needs for safety and security, self-realization and social recognition. The fundamental orientation of research and state administration on the issues of security and safety and its management came after major terrorist attacks in the U.S. 11.09.2001, 11.3.2004 in Madrid, 3.9.2004 in Beslan, 7.7.2005 in London, etc., after which mankind fully realized what security means for it and its development and what represents the highest value for it. Current knowledge and experience (Procházková, 2011b) shows that we know that in order to achieve the desired state of each system, i.e. including the human system, and for its development, it is important to set goals and procedures for achieving them, which are dependent on the resources, powers and means that are never sufficient. Therefore, it is necessary to focus on priorities, and to manage resources, forces and means in time and space. In addition to all above, it is necessary to know the territory and its protected interests, possible disasters that threaten it, a way of threatening, available resources, sources of power and resources (Procházková, 2011a). Following paragraphs focus on the facts we need to know about the territory and the scope of details.

\section{The knowledge base}

A concept is a common feature or characteristic. Concepts are vital to the development of scientific knowledge. Concepts, as abstract units of meaning, play a key role in the development and testing of theories. The paper presents concept of the EU security as a schema containing both, the items and the data that are taken into account for the EU security. It contains vision on the EU security and on its provision. On the basis of assessment of data and findings from professional publications, the list 
of each is e.g. in book (Procházková, 2011a), the concept is compiled by application of comprehensive approach (Procházková, 2011c), aims and principles given in the UN concept HUMAN SYSTEM SAFETY (UN, 1994) and in the EU concept SAFE COMMUNITY (EU, 2012).

The evaluation of collected relevant data described above shows that the real security concept contains:

1.Present cognition of problems of safety, security and sustainable development and set of findings on the EU management, i.e.: historical concepts and experience; management tools (co-ordination and responsibility matrices, fundamental functions of the EU, Member States, regional and local governments - public affairs management, private organisation affairs management, citizen education, specific education of technical and managerial workers, technical, health, environmental, cyber and other standards, norms and rules, inspections and audits, executive units for emergency situations coping, systems for coping the emergency and critical situations, security, emergency, continuity and crisis planning, research and development, science on safety and on human system security; safety management including measures and activities for ensuring the security and sustainable development; levels of safety management; data, information and knowledge; decision-making principles (phases, types and methods of decisionmaking, decision-making on public assets, rules for decision-making and decision support systems); safety management system; programme for safety increasing; golden rules for safety management; groundwork's for application of process management at safety management; and strategy and strategic management.

2. Terms (definition of security, safety, sustainable development, hazard, risk etc.).

3. Human system assets, i.e.: basic public assets; human system characteristics; and conclusions for safety management.

4. Reality that sources of disasters, i.e. phenomena that from some size can disrupt the EU security, are the results of five different processes in human system (Procházková, 2011a), Figure 1.

5.Description of disasters, emergencies and connections linked with management, i.e.: disasters (their causes, types, sizes, characteristics; summary of general findings on disasters; and action of disasters on human system); emergencies (categories, category characteristics); human system vulnerabilities; and emergency defeat principles.
6. Rules for negotiation (trade-off) with risks, i.e.: problems connected with safety of assets; set of knowledge necessary for safety of assets; hazard and risk characteristics and determination; life with risks (partial, integrated and integral risk, analysis and assessment of risks; methods used at analysis and assessment of risks; risk acceptability, qualified procedure for comparison of risks, processing the risk assessment results to form suitable for decision-making, risk assessment); risk management and safety management (risk engineering, security engineering, safety engineering, SoS safety engineering, risk management model, safety management model).

7. Relevant subsystems of the EU, Member States, regional and local governments for safety management and their support, i.e.: safety management stages; planning (demands, security planning, space planning, land-use planning, emergency, continuity and crisis planning, renewal planning); systems for decision support; and security documentation.

8. Selected aspects connected with safety and crisis management, i.e.: information transfer and communication principles; international co-operation; and humanitarian aid principles.

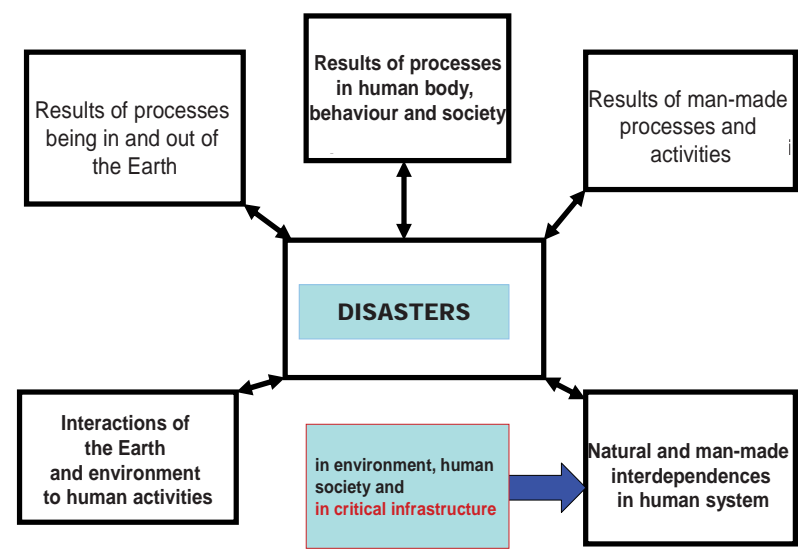

Fig. 1 Sources of disasters in the Human system (Procházková, 2011a)

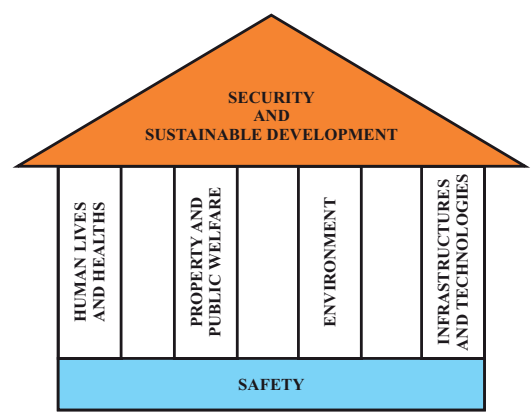

Fig. 2 Human system public assets (Procházková, 2011a, d) 
9. Legislation of the EU and the Members States for safety management, territory development and crisis management, i.e.: basic legislation; special legislation for crisis management; and crisis management bodies.

10. Safety management system of the EU and the Member States, i.e. demands; structure and relevant elements (public administration, police, fire-fighters, army, citizens).

In these parts, the concept of the EU security shall contain relevant knowledge and approaches as:

1. There is a set of human system public assets that are mutually dependent, Fig. 2 (Procházková, 2011a, d).

2. There is a set of documented disasters (Procházková, 2011a, d); about 77 different types.

3. The disasters affect public assets by various ways, and therefore, the protection must be correctly directed (Procházková, 2011a, d).

4. At ensuring the human system asset protection, the All Hazard Approach is used [6]; it was accepted by the EU (Procházková, 2011a).

5. For safety management, the causal relationship „disaster - emergency“ is important, Fig. 3 (Procházková, 2011a, d).

6.It is the reality that humans have limited possibilities in protection of public assets against disasters; they only contain them to certain size of disaster level that is marked by the term the design disaster (the protection is aimed to impacts of this size for each disaster type). If these levels are exceeded, the manifestation of interdependences starts, Fig. 4 (Procházková, 2011a, d). The special protection during the emergency is only planned and arranged for human lives and health and property (see national legislations).

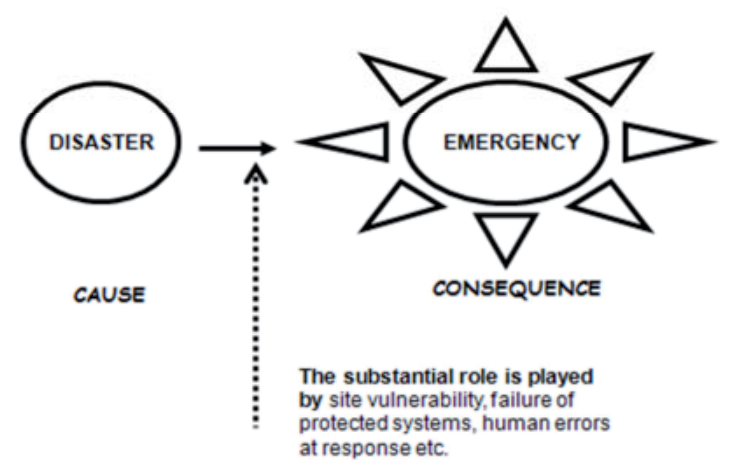

Fig. 3 Relationship cause vs. consequence

(Procházková, 2011 b, d)

7. The humans perform different measures and activities with the aim to cope with the disasters, Fig. 5 (Procházková, 2011a, d).
8. The EU security can be reached only by systematic, proactive and permanent effort correctly directed to important targets (Procházková, 2011a).

9. The EU and its Member States have management of state (i.e. human system) with three levels, Fig. 6 (Procházková, 2011a, d).

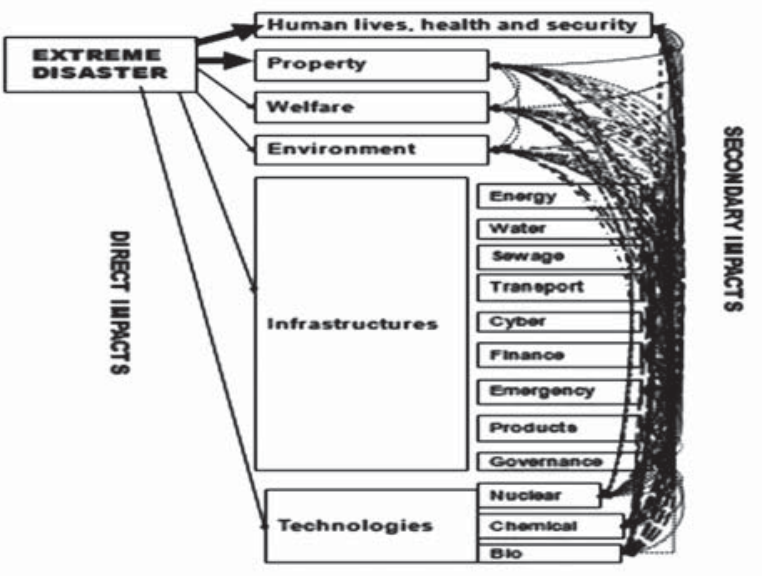

Fig. 4 Extreme (beyond design) disaster impacts on public assets. Protection measures and activities are prepared only for impacts denoted by bold arrow. Secondary impacts are caused by cascade failures of infrastructures (Procházková, 2011b, d)

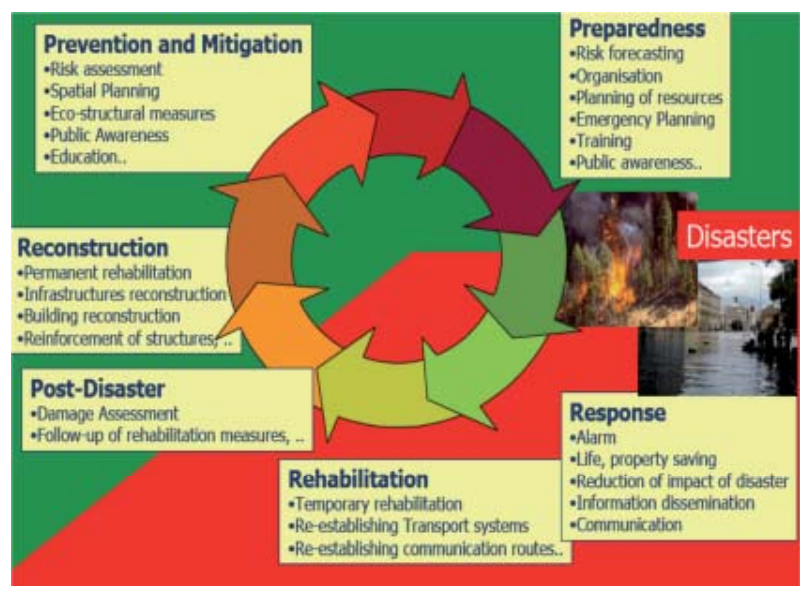

Fig. 5 Different measures and activities performed by humans with the aim to cope with the disasters (Procházková, 2011a)

10. The EU and its Member States have special legislation for safety management; example is given in Figure 7 (Procházková, 2011a, d).

11. The methods of risk identification, risk analysis, risk management and risk engineering depend on the following requirements (distinguished methods exist for: risk reduction in closed system only considering the technical causes of risks; risk reduction in closed system considering 
technical and human factor causes of risks; ensuring the system security without respecting the system vicinity security; ensuring the system safety - system and its vicinity are safe; ensuring the system of systems ( $\mathrm{SoS}$ ) safety - overlapping systems and their vicinity are safe) (Procházková, 2011a, d).

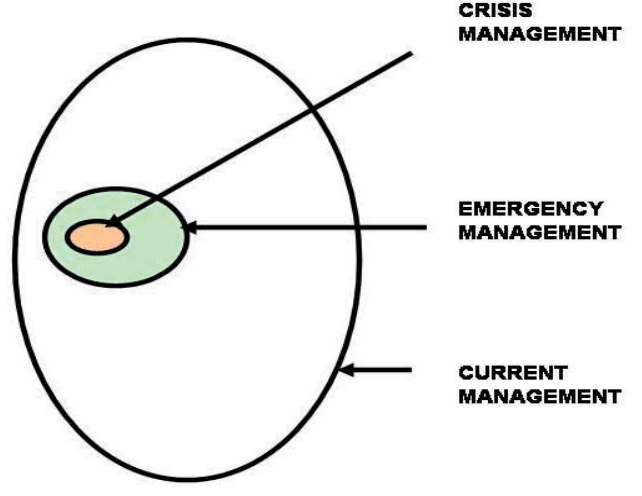

Fig. 6 Three level state (i.e. human system) management (Procházková, 2011c, d)

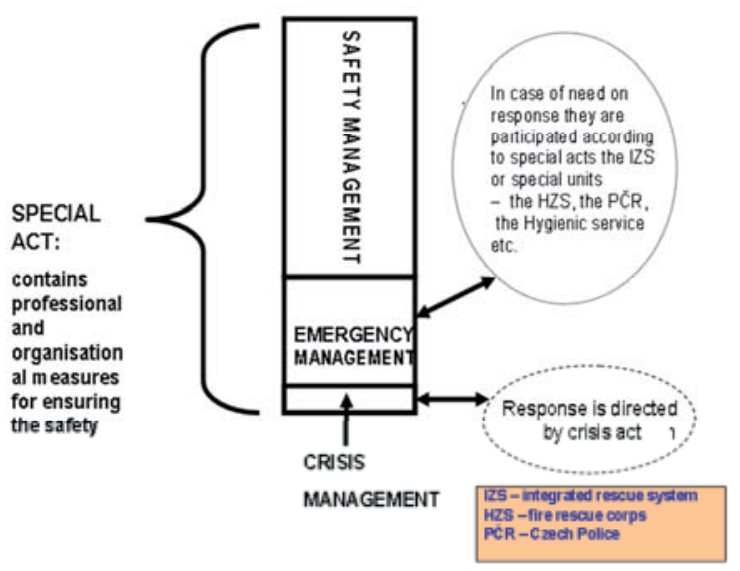

Fig. 7 Example of legislation structure for ensuring the safety in various situations that is in force in the

Czech Republic (Procházková, 2011a, d)

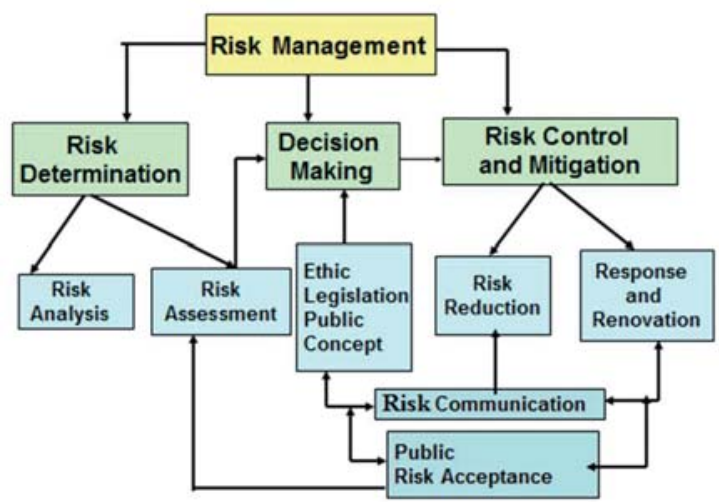

Fig. 8 Model of risk management of territory (Procházková, 2011a, d, f)
12. The EU can be the global security actor only if it respects principals of SoS safety in management of risks and in engineering disciplines implementing the measures and activities keeping the risk on acceptable level.

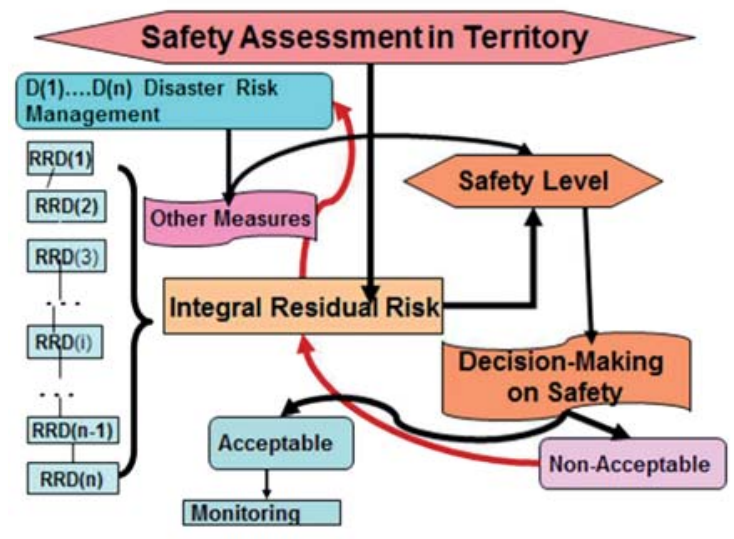

Fig. 9 Model of safety management of territory (RRD(i) - risk from i-th relevant disaster

(Procházková, 2011a, d, f)

\section{Results}

\section{Role of advanced risk engineering}

Risk engineering ensures realisation of aims of risk management. The development of engineering types is shown in Fig. 8 (Procházková, 2011f). The key concepts of engineering directed to safety are:

1. The approaches are based on risk - the work intensity and documentation is adequate to the risk level.

2. The professional approach is based on reality that they are only considered critical attributes of quality and critical parameters of process.

3. The problem solution is oriented to critical items - they are followed and managed critical aspects of technical systems ensuring the consistence of system operations.

4. Verified quality parameters are included in project proposal.

5. The accent on quality engineering procedures - it must prove the accuracy of selected procedures under given conditions.

6. The aim on safety upgrade - permanent improving the processes with the use of the analysis of root causes of malfunctions and failures.

From given facts it follows that engineering types given in Fig. 8 are multidisciplinary and interdisciplinary disciplines, and therefore, they use 
various methods, tools and techniques. The safety engineering as very advanced risk engineering type respects the co-existence of systems with different nature (SoS), and so fulfils present demands of humans.

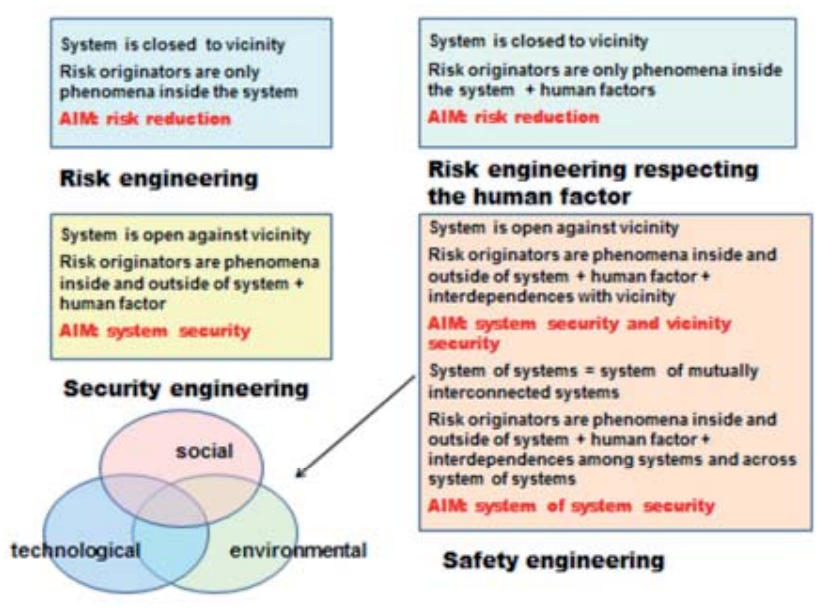

Fig. 10 Engineering types

For the above given principles respect, relevant data sets and only verified methods, that provide outputs with designated testified competence, must be used. Because in a group of cases the vagueness in data is not well coped with, the procedures designated as good practice procedures/good engineering practice procedures are used. It goes on modus operandi procedures in individual domains that based on experience lead to a good result. The given procedure is used in cases in which any unified procedure was not approved. It is often used at measurements in laboratories, negotiation with humans etc.

Good engineering practice (good engineering procedure) is then defined as a set of engineering methods and standards that are using during the life cycle of technical system with the aim to reach appropriate and cost-efficient solution. It is supported by fit documentation (conceptual documentation, diagrams, charts, manuals, testing reports etc.).

In a given context, the engineering expertise is the expression of capability to: apply knowledge of mathematics, science and engineering; propose and realize experiments; analyse and interpret data; propose components or whole system according to requirements and under the frame of realistic limitations identify, formulate and solve engineering problems; ensure the effective communication; comprehend impacts of engineering solutions in broader context; use the advanced tools and methods in engineering practice; adhere professional and operational responsibilities and ethics; lead the interdisciplinary team.
The aim of risk engineering has been to reduce risks of considered systems. The risk is expressed as a probable size of losses, harms and detriments of followed assets that caused a given disaster with specified size that is calculated for a certain time unit (usually 1 year) and a certain territory unit. At risk calculation, we distinguish whether the risk realisation develops forever identically or differently in dependence on momentary local and time asset conditions. In the first case we determine a kind of mean risk value and its validity for use in practice we connect with condition that the less unfavourable case is considered (the given approach is in norms and standards based on deterministic approach). The other case corresponds to the reality better, and therefore it is considered at groundwork preparation for strategic management directed to safety. Are determined Variant scenarios of risk realisation and their occurrence probabilities are determined; from these the mean value and its dispersion is determined by clear mathematical procedure (the given approach is in norms and standards based on stochastic approach). The actual reality, however, is more complicated because, as stated above, the data have uncertainties and vagueness that connect with variability of conditions in time and space. At present, exactly defined heuristic procedures are used (Procházková, 2011b, 2012).

Problems that we must solve in a given context consist in obtaining the knowledge and in determination who is expert, see discussion in ESREL 2011 (Bérenguer, 2012).

\section{What is necessary to improve?}

Recent FOCUS project outputs (EU, 2012) show that the main EU problems, i.e. the EU vulnerabilities are the following: all hazard approach is not systemically applied; some disasters are underestimated; systemic, strategic and proactive management is not implemented into practice; gaps in risk management, risk engineering and in tradeoff with risks; research does not determine priority orientations, its targets are influenced by politicians or lobbies; application procedures and orientation of strategies are not regularly verified; reasonable strategy for disaster management is missing; the disaster management does not often respect disaster life cycle; accent to problem solving is missing, still only a lot of discussions on problems; lack of resources; lack of instruments for ensuring the EU finance stability; lack of management supporting the public protection and sustainable development. In the frame of FOCUS project, the outputs will be proposals of measures and activities for removing the identified deficiencies. 


\section{Conclusion}

The concept respecting the above mentioned knowledge and approaches is the fundament on which the FOCUS project is performed. It gives the review of the present EU internal framework and the proposal of domains that are important for the EU internal framework upgrade with the aim to strengthen the EU role in the world in future. According to good practice principles, only systematic, permanent and well directed measures and activities guarantee the procuration of good EU role in the world now and in future.

\section{Acknowledgments}

The research was supported by the Czech Technical University, Faculty of Transport Science (Institute for Security Technologies and Engineering), by the EU - project FOCUS, grant No 261633 and by the Ministry of Education of the Czech Republic, grant No 7E11072. Thank you for support

\section{References}

BÉRENGUER, CH., GRALL, A., SOARES, C.G. (2012). Advances in Safety, Reliability and Risk Management. London: Taylor \& Francis Group, 2012, 3068 p. ISBN 978-0-415-68379-1.

EU (2012). The FOCUS project outputs. EU grant No 261633 [online]. FOCUS Project, 2010-2012 [cit. 2012-0214]. Available at: http://www.focusproject.eu.

FEMA (1996). Guide for all-hazard emergency operations planning. State and Local Guide (SLG) 101. FEMA, Washington 1996.

MASLOW, A. H. (1954). Motivation and personality. New York: Harper, 1954, 236p.

NICHOLSON, J., DUNPHY, P., COVENTRY, L., BRIGGS, P., OLIVIER, P. (2012). A security assessment of tiles: a new portfolio-based graphical authentication system. In: Proceedings of the 2012 ACM on Human Factors in Computing Systems (CHI EA '12). ACM, New York, NY, USA, 1967-1972. DOI=10.1145/2212776.2223737 http://doi.acm.org/10.1145/2212776.2223737.

PROCHÁZKOVÁ, D. (2008). Safety of Critical Infrastructure. SPEKTRUM, Ostrava. 2008, Vol. 8, No. 2. ISSN 1211-6920 (in Czech).

PROCHÁZKOVÁ, D. (2011a). Strategic safety management of territory and organisation. Praha: ČVUT, 2011, 483 p. ISBN 978-80-01-04844-3 (in Czech).

PROCHÁZKOVÁ, D. (2011b). CVUT report to WP3 FOCUS. Praha: CVUT Archives, 2011, 61p.

PROCHÁZKOVÁ, D. (2011c). Effectively mitigating and managing the risk to public assets. In Advances in Safety, Reliability and Risk Management. Troyes, France: CRC Press, Taylor \& Francis Group, a Balkema Book, pp. 1709-1716. ISBN 978-0-203-13510-5.

PROCHÁZKOVÁ, D. (2011d). Final CVUT report to WP2 FOCUS. Praha: CVUT Archives, 2011, 381p.

PROCHÁZKOVÁ, D. (2011f). Risk analysis and risk management. Praha: ČVUT, 2011, 405 s. ISBN 978-80-0104841-2 (in Czech).

PROCHÁZKOVÁ, D. (2011g). Methods, Tools and Techniques for Risk Engineering. ČVUT, Praha 2011, 369 p. ISBN: 978-80-01-04842-9.

PROCHÁZKOVÁ, D. (2012a). Selected Methods of safety Engineering. SPEKTRUM, Ostrava. 2012, Vol. 11, No 1, pp 41-47. ISSN 1211-6920.

PROCHÁZKOVÁ, D. (2012b). Procedures and methodologies of engineering disciplines directed to safety. Ostrava: SPBI, 2012, ISBN 978-80-7385-111-8, in print (in Czech).

ROGERS, J. (2011). Language Choice for Safety Critical Applications. 81-90. DOI=10.1145/2070336.2070363 http://doi.acm.org/10.1145/2070336.2070363.

UN (1994). Human development report [online]. United Nations, New York, 1994 [cit. 2012-02-14]. Available at: http://hdr.undp.org/en/media/hdr_1994_en_contents.pdf. 